\title{
Microbiota intestinal e desempenho de frangos alimentados com rações elaboradas com sorgo ou milheto e complexo enzimático
}

\author{
[Intestinal microflora and broiler performance fed with sorghum or pearl millet \\ with enzymatic complexes] \\ P.R.S.C. Leite ${ }^{1}$, N.S.M. Leandro ${ }^{2 *}$, J.H. Stringhini ${ }^{2}$, E.S. Souza ${ }^{2}$, M.B. Café $e^{2}$, \\ F.B. Carvalho ${ }^{2}$, M.A. Andrade ${ }^{2}$ \\ ${ }^{1}$ Instituto Federal Goiano - Ceres, GO \\ ${ }^{2}$ EVZ-UFG - Goiânia, GO \\ RESUMO
}

\begin{abstract}
Avaliou-se a suplementação enzimática em rações contendo milheto ou sorgo sobre a microbiota intestinal e o desempenho de frangos. Foram alojados 420 pintos - ensaio de microbiota - e 1.200 pintos - ensaio de desempenho -, submetidos aos tratamentos com sorgo ou milheto suplementados ou não com complexo enzimático. O delineamento utilizado foi inteiramente ao acaso, com sete repetições de 15 aves cada, para o ensaio de microbiota, e em blocos ao acaso, com cinco repetições e 60 aves por parcela para desempenho. Foram realizadas pesquisas de bactérias Gram-negativas e contagem do número total de microrganismos aeróbios do intestino delgado. A suplementação enzimática não afetou a microbiota intestinal de frangos aos 14 e 28 dias de idade. Houve efeito da suplementação enzimática nas dietas com sorgo para conversão alimentar na fase pré-inicial. Nas dietas com milheto, a suplementação melhorou o ganho de peso no período de um a 35 dias de idade. No período total de criação, de um a 42 dias, não foi observado efeito da suplementação para milheto ou sorgo. Conclui-se que a utilização da suplementação de enzimas em rações com sorgo ou milheto pode melhorar os resultados de desempenho, dependendo da fase de crescimento de frangos de corte.
\end{abstract}

Palavras-chave: frango de corte, desempenho, ingrediente alternativo, microbiota intestinal

\begin{abstract}
Two experiments were conducted to examine the supplementation enzyme in broilers fed with sorghum or pearl millet. The intestinal microflora and broiler performance was conducted with 420 and 1.200 broiler chickens, respectively. The treatments consisted of sorghum or pearl millet diet with enzymatic complex. The microflora assay consisted of 15 birds per experimental unit in completed randomized delineament, with seven replicates, and the performance study consisted of 60 birds per experimetal unit in a randomized block design, with five replicates. A study of bacteria negative-gram and total number bacteria aerobic in the small intestine was carried out. The averages were compared by contrasts (performance) and the Kruskal-Wallis (bacteria) tests applied for the research. The enzyme supplementation did not affect the broiler intestinal microflora at the age of 14 and 28 days. Feed conversion in the pearl millet diets supplemented with enzymes was better in the initial phase. The body weight was better to treat enzymatic complex in diets pearl millet (at age of 1-35 days), however, at the age of 1 to 42 days there was no effect of supplementation for millet or sorghum. The results showed that the sorghum or pearl millet diets supplemented with enzymes are a viable strategy to improve the nutritional value of the diets and performance results depending on the age of the broilers.
\end{abstract}

Keywords: broiler, performance, alternative ingredient, intestinal microflora

Recebido em 6 de setembro de 2011

Aceito em 20 de julho de 2012

*Autor para correspondência (corresponding author)

E-mail: mogyca@vet.ufg.br 


\section{INTRODUÇÃO}

O milho é o principal ingrediente utilizado nas rações de aves como fonte de energia, no entanto o mercado do grão de milho é instável, e o seu preço elevado provoca aumento no custo da ração. Com isso, alimentos alternativos que possam substituir o milho nas rações de frango de corte são opções para reduções dos custos das rações. O milheto e o sorgo são ingredientes energéticos que podem substituir o milho nas rações de frango de corte e, além do menor preço, esses ingredientes apresentam um bom perfil de proteína bruta, aminoácidos essenciais e proporcionam resultados de desempenho semelhantes ao do milho (Morais et al., 2002; Rostagno et al., 2005).

Alguns estudos mostram que a inclusão de enzimas exógenas melhora a disponibilidade de nutrientes da ração (Brito et al., 2006; Oliveira et al., 2007) e o desempenho dos frangos (Odetallah et al., 2006; Olukosi et al., 2007) e pode melhorar a relação custo:benefício na formulação de ração de aves (Toledo et al., 2007). As enzimas exógenas podem ser destinadas a complementar a ação das enzimas digestivas endógenas, a tornar os nutrientes mais disponíveis para absorção e a aumentar o valor energético dos ingredientes, reduzindo a variação da qualidade nutricional (Bedford, 2000). Enzimas atuam diretamente sobre substratos específicos e na degradação da parede celular dos vegetais, permitindo o acesso dos substratos que, por estarem no conteúdo celular, tornar-seiam indisponíveis para o aproveitamento pelos animais monogástricos.

Existem no mercado produtos enzimáticos com atividade única ou combinados com várias enzimas, na forma de complexo. As enzimas, por apresentarem especificidade com os substratos, quando utilizadas na dieta de frango de corte na forma de complexo enzimático, podem melhorar o aproveitamento dos nutrientes (Oliveira et al., 2007). Alguns estudos mostram o efeito positivo da suplementação de complexo enzimático em rações de frango de corte sobre a digestibilidade dos nutrientes da ração e o desempenho dos frangos (Opalinsk et al., 2006; Reddy et al., 2008).

As enzimas exógenas são utilizadas com a finalidade de diminuir os efeitos adversos dos polissacarídeos não amídicos (PNAs) e do fitato, considerados fatores antinutricionais, que afetam a digestibilidade dos nutrientes das rações e, consequentemente, o desempenho dos frangos (Bedford, 2000). O sorgo apresenta composição semelhante ao milho com relação aos PNAS, em torno de 9\% (Malathi e Devegowda, 2001). Os polissacarídeos não amídicos podem ser hidrolisados com a ação das enzimas exógenas, proporcionando maior degradação da parede celular dos ingredientes utilizados nas rações de aves com melhor coeficiente de digestibilidade da energia bruta (Tejedor et al., 2001; Gracia et al., 2003).

Por outro lado, com a melhor digestão de componentes da parede celular dos vegetais, as enzimas exógenas podem alterar a composição da microbiota intestinal e, assim, melhorar a saúde intestinal de frangos de corte (Danicke et al., 1999). Uma melhor absorção dos nutrientes diminui a quantidade de substrato no intestino, o que resulta em alteração na quantidade e na composição da população microbiana. Mathlouthi et al. (2002) observaram redução no número de unidades formadoras de colônias de bactérias anaeróbias facultativas e Escherichia coli no ceco de frangos, quando as rações formuladas à base de trigo e cevada foram suplementadas com as enzimas xilanase e betaglucanase.

Objetivou-se avaliar a suplementação de um complexo enzimático comercial em rações formuladas com sorgo ou milheto sobre a microbiota intestinal e o desempenho de frangos, durante todo o período de criação.

\section{MATERIAL E MÉTODOS}

O experimento para avaliação da microbiota intestinal foi realizado com 420 pintos de corte, machos de um dia de idade, da linhagem Cobb, alojados em baterias metálicas instaladas em galpão de alvenaria. Os tratamentos avaliados consistiam de dois tipos de ingredientes energéticos na ração, milheto ou sorgo, associados à suplementação de um complexo enzimático, totalizando quatro tratamentos, sendo: ração formulada com sorgo sem enzimas, ração formulada com sorgo e com enzimas, ração formulada com milheto e sem enzimas e ração formulada com milheto e com enzimas. O delineamento utilizado foi inteiramente ao acaso, 
com sete repetições de 15 aves por unidade experimental.

As aves, até os 28 dias de idade, receberam água e ração à vontade, durante todo o período experimental. As rações experimentais (Tab. 1) foram formuladas de acordo com a matriz da composição de alimentos de uma empresa comercial para atender os níveis nutricionais propostos pela empresa e de acordo com cada fase de criação de frangos - pré-inicial, inicial e crescimento. Na fase final, 36 a 42 dias de idade, foi utilizada uma ração única, elaborada com farelo de soja e milho, sem adição de enzimas.

Tabela 1. Composição percentual e calculada das rações experimentais para as diferentes fases de criação

\begin{tabular}{|c|c|c|c|c|c|c|}
\hline \multirow[t]{2}{*}{ Ingrediente (\%) } & \multicolumn{2}{|c|}{$\begin{array}{l}\text { Pré-inicial } \\
\text { (1-7 dias) }\end{array}$} & \multicolumn{2}{|c|}{$\begin{array}{c}\text { Inicial } \\
(8-21 \text { dias })\end{array}$} & \multicolumn{2}{|c|}{$\begin{array}{l}\text { Crescimento } \\
\text { (22-35 dias) }\end{array}$} \\
\hline & Sorgo & Milheto & Sorgo & Milheto & Sorgo & Milheto \\
\hline Sorgo & 51,1 & - & 56,55 & - & 70,12 & - \\
\hline Milheto & - & 53,3 & - & 60,56 & - & 66,29 \\
\hline Farelo de soja & 22,5 & 9,6 & 12,68 & 13,67 & 4,31 & - \\
\hline Soja integral & 20,0 & 30,6 & 23,22 & 14,73 & 9,39 & 22,47 \\
\hline F. carne e ossos & 4,5 & 4,40 & 4,47 & 4,53 & 3,80 & 2,80 \\
\hline F. de sangue & - & - & 1,33 & 1,33 & 2,66 & - \\
\hline F. de vísceras & - & - & - & - & 2,47 & 2,46 \\
\hline F. de pena & - & - & - & - & 2,54 & - \\
\hline Gordura de aves & - & - & - & 3,33 & 2,67 & 4.00 \\
\hline Sal comum & 0,36 & 0,32 & 0,30 & 0,27 & 0,23 & 0,23 \\
\hline Calcário calcítico & 0,34 & 0,47 & 0,33 & 0,40 & 0,23 & 0,66 \\
\hline DL-Metionina & 0,30 & 0,29 & 0,30 & 0,26 & 0,31 & 0,28 \\
\hline L-Lisina & 0,22 & 0,32 & 0,30 & 0,40 & 0,67 & 0,31 \\
\hline Supemento Min.Vit. ${ }^{1}$ & 0,57 & 0,57 & 0,52 & 0,52 & 0,50 & 0,50 \\
\hline Total & 100,00 & 100,00 & 100,00 & 100,00 & 100,00 & 100,00 \\
\hline \multicolumn{7}{|l|}{ Composição calculada: } \\
\hline Proteína bruta $(\%)$ & 24,4 & 24,4 & 22,5 & 22,5 & 19,6 & 19,6 \\
\hline $\begin{array}{l}\text { Energia metabolizável } \\
\text { (Mcal/kg) }\end{array}$ & 3,03 & 3,03 & 3.120 & 3.120 & 3.299 & 3.299 \\
\hline Lisina total $(\%)$ & 1,50 & 1,50 & 1,33 & 1,33 & 1,21 & 1,21 \\
\hline Met. total $(\%)$ & 0,74 & 0,74 & 0,66 & 0,66 & 0,63 & 0,63 \\
\hline Met.+Cist. total (\%) & 1,11 & 1,11 & 1,00 & 1,00 & 0,946 & 0,946 \\
\hline Cálcio (\%) & 0,99 & 0,99 & 0,97 & 0,97 & 0,94 & 0,94 \\
\hline Fósforo disp. (\%) & 0,50 & 0,50 & 0,50 & 0,50 & 0,45 & 0,45 \\
\hline
\end{tabular}

${ }^{1}$ Suplemento vitamínico e mineral (por kg de produto): vit. A, 10.000.000UI; vit. D3, 2.000.000UI; vit. E, 12.500mg; vit. K3, 2.500mg; vit. B1, 2.400mg; vit. B2, 6.000mg; vit. B6, 3.200mg; vit. B12, $12.000 \mathrm{mcg}$; ác. fólico, $1.000 \mathrm{mg}$; pantotenato $\mathrm{Ca}, 12.500 \mathrm{mg}$; niacina, $30.000 \mathrm{mg}$; antioxidante, $15 \mathrm{~g}$; selênio, 200mg; veículo q.s.p., $1.000 \mathrm{~g}$; cobre, $12.000 \mathrm{mg}$; ferro, $40.000 \mathrm{mg}$; iodo, $1.000 \mathrm{mg}$; manganês, $65.000 \mathrm{mg}$; zinco, $50.000 \mathrm{mg}$; veículo q.s.p., $1.000 \mathrm{~g}$.

A adição enzimática foi realizada com um complexo enzimático comercial composto pelas enzimas amilase, pectinase, betaglucanase, pentosanase, celulase, protease e fitase, na proporção de $200 \mathrm{~g} /$ ton de ração. As rações foram fareladas, e o complexo enzimático foi adicionado durante a mistura dos ingredientes.

Para a avaliação da microbiota intestinal das aves, foram utilizadas duas aves por parcela, aos 14 e 28 dias de vida. As aves foram sacrificadas por deslocamento cervical, e foram coletados os conteúdos do intestino delgado para contagem total de bactérias aeróbicas mesófilas e Gramnegativas com posterior identificação de bactérias do grupo coliformes. Foi formado um pool das amostras do conteúdo intestinal, e retirado $0,5 \mathrm{~g}$ da amostra, a qual foi imediatamente transferida para tubos de ensaio contendo $4,5 \mathrm{~mL}$ de solução salina tamponada esterelizada a $0,1 \%$, determinando-se, assim, a diluição $10^{-1}$, seguida de diluições sucessivas até a diluição $10^{-7}$. Das diluições $10^{-4}, 10^{-5}$ e $10^{-7}$, foi vertido $1,0 \mathrm{~mL}$ de cada diluição para placas de Petri, e $15 \mathrm{~mL}$ de ágar padrão para contagem foram previamente fundidos e resfriados a $45^{\circ} \mathrm{C}$. 
As placas contendo o inóculo e o meio de cultura foram homogeneizadas e, após completa solidificação do meio de cultura, as placas invertidas foram incubadas a $35^{\circ} \mathrm{C}$ por 48 horas. Foram selecionadas placas com 30 a 400 colônias, as quais foram contadas em contador de colônias manual; o número de UFC foi calculado pela média aritmética da contagem das placas e multiplicado pelo inverso da diluição inoculada.

Para análises de bactérias Gram-negativas das diluições $10^{-4}$ e $10^{-6}, 0,1 \mathrm{~mL}$ foi transferido para placas de Petri contendo ágar eosina azul de metileno (EMB), sendo realizado o plaqueamento em superfície. A partir do crescimento de colônias típicas e atípicas, segundo Brasil (2003), colônias foram transferidas para ágar tríplice açúcar ferro (TSI) e, posteriormente, submetidas ao teste de $\mathrm{KOH}$ a $3 \%$, teste de ureia, indol, vermelho de metila, citrato de Simnons, glicose e malonato para confirmação de bactérias do grupo coliformes (Escherichia, Klebsiella, Citrobacter e Enterobacter). Para a análise estatística, as médias aritméticas das unidades formadoras de colônias (UFC) foram comparadas utilizando-se o teste não paramétrico de Kruskal-Wallis.

O ensaio de desempenho foi realizado no aviário experimental, com 1.200 pintos de corte, machos da linhagem Cobb, alojados em dois galpões de alvenaria com $24 \times 6,65 \mathrm{~m}$ de dimensões internas, divididos em 16 boxes de 2,10x2,50m cada $\left(5,25 \mathrm{~m}^{2}\right)$. Cada boxe apresentava um bebedouro pendular e dois comedouros tubulares infantis até o sétimo dia de idade e um adulto a partir desse período. A densidade de alojamento em cada boxe foi de 12 aves $/ \mathrm{m}^{2}$.

Foi utilizado o delineamento em blocos ao acaso, totalizando quatro tratamentos com cinco repetições e 60 aves por unidade experimental. Foram avaliados: peso médio, ganho de peso, consumo de ração e conversão alimentar dos frangos nas diferentes fases de criação. A conversão alimentar foi calculada pela relação entre o ganho de peso e o consumo de ração, sendo utilizado como critério de correção o peso das aves mortas nas diferentes fases e no período total.

As variáveis de desempenho foram submetidas à análise de variância, utilizando-se o programa estatístico SAS $^{\circledR}$ (Statistical..., 2000), e, para comparação de médias, usou-se o teste de contrastes.

\section{RESULTADOS E DISCUSSÃO}

O tipo de ingrediente energético utilizado na ração (sorgo ou milheto) não influenciou $(\mathrm{P}>0,05)$ a presença de bactérias aeróbias e coliformes no intestino delgado de frangos (Tab. 2). Do mesmo modo, não houve efeito $(P>0,05)$ da adição de enzimas na ração sobre a contagem dessas bactérias no intestino delgado de frangos de corte, nas idades de 14 e 28 dias. Estes resultados sugerem que a adição de enzimas em rações elaboradas com milheto ou sorgo não proporcionou alterações nas condições intestinais em relação aos microrganismos pesquisados no intestino delgado. Resultados semelhantes foram observados por Gao et al. (2008), que, ao avaliarem a adição da enzima xilanase em rações elaboradas com trigo, não verificaram a influência dessa enzima sobre a contagem de bactérias coliformes no ceco de frangos, aos 21 dias de idade.

Sarica et al. (2005) reportaram diminuição no número de unidades formadoras de colônias de Escherichia coli no intestino delgado de frangos aos 42 dias de idade, quando associaram a enzima xilanase com antibiótico promotor de crescimento (flavomicina) em dietas à base de trigo. Segundo Santos Jr. e Ferket (2007), a xilanase, ao degradar a molécula de xilano em unidades menores, promove alguns benefícios, entre eles a diminuição da fermentação intestinal pela menor quantidade de polissacarídeos não amídicos no intestino e menor viscosidade intestinal com maior atuação das enzimas digestivas. 
Tabela 2. Contagem de bactérias aeróbias e coliformes, aos 14 e 28 dias de idade, em amostras de intestino delgado de frangos alimentados com dietas contendo sorgo ou milheto suplementadas com complexo enzimático (CE)

\begin{tabular}{|c|c|c|}
\hline \multirow[b]{2}{*}{ Tratamento } & \multicolumn{2}{|c|}{14 dias de idade } \\
\hline & $\begin{array}{c}\text { Bactérias aeróbias } \\
\log (\mathrm{UFC} / \mathrm{g})\end{array}$ & $\begin{array}{c}\text { Coliformes } \\
\text { Log }(\mathrm{UFC} / \mathrm{g})\end{array}$ \\
\hline Sorgo & 6,680 & 7,522 \\
\hline Sorgo $+\mathrm{CE}$ & 7,542 & 7,849 \\
\hline Milheto & 7,356 & 7,033 \\
\hline Milheto + CE & 7,713 & 6,334 \\
\hline \multirow[t]{2}{*}{ Valor de $\mathrm{P}$} & ns & ns \\
\hline & \multicolumn{2}{|c|}{28 dias de idade } \\
\hline Tratamento & $\begin{array}{c}\text { Bactérias aeróbias } \\
\log (\mathrm{UFC} / \mathrm{g})\end{array}$ & $\begin{array}{c}\text { Coliformes } \\
\text { Log (UFC/g) }\end{array}$ \\
\hline Sorgo & 6,977 & 10,256 \\
\hline Sorgo + CE & 6,981 & 10,164 \\
\hline Milheto & 6,831 & 8,845 \\
\hline Milheto + CE & 6,981 & 9,026 \\
\hline Valor de $\mathrm{P}$ & ns & ns \\
\hline
\end{tabular}

$\mathrm{P}=$ probabilidade; teste de Kruskal-Wallis (5\%).

As diferenças verificadas entre pesquisas e os resultados encontrados neste estudo podem ser explicados pelas variações na composição das rações experimentais com relação aos ingredientes utilizados. A colonização bacteriana é dependente da dieta, especialmente da fibra, que é fonte principal de substrato para o metabolismo bacteriano. Ressalta-se que pesquisa realizada por Apajalahti et al. (2001), com frangos alimentados com dietas contendo trigo, constataram que a dieta foi o fator mais importante na determinação da comunidade microbiana, no ceco das aves. Mathlouthi et al. (2002) relataram que rações à base de trigo e cevada, ricas em polissacarídeos não amídicos, proporcionaram aumento na contagem de bactérias anaeróbias facultativas, Escherichia coli e Lactobacillus, no ceco de frangos de corte, quando comparadas com as rações formuladas com milho, em frangos com 25 dias de idade.

Aves alimentadas com dietas ricas em polissacarídeos não amídicos (PNAs) podem apresentar aumento da viscosidade do intestino delgado e diminuir o contato entre enzimas e substrato e reduzir a absorção de nutrientes. Assim, os PNAs podem ter efeito negativo sobre a microbiota intestinal com maior fermentação microbiana (Bedford, 2000; Santos Jr. e Ferket, 2007).
O sorgo é um ingrediente semelhante ao milho em relação aos níveis de PNAs, sendo que as porcentagens de PNAs em relação ao total de carboidratos encontrados no milho e sorgo foram de 9,40 e 9,32\%, respectivamente (Malathi e Devegowda, 2001). Já alimentos ricos em fibra apresentam maiores quantidades de PNAs, como farelo de girassol (41\%), farelo de canola (39\%), trigo $(66 \mathrm{~g} / \mathrm{kg}$ de matéria seca), centeio $(101 \mathrm{~g} / \mathrm{kg}$ de matéria seca), triticale $(77 \mathrm{~g} / \mathrm{kg}$ de matéria seca), farelo de arroz (59,7\%) (Malathi e Devegowda, 2001). Wang et al. (2005) relataram que aves alimentadas com dietas à base de trigo (ricas em PNAs) não podem secretar enzimas suficientes para degradar PNAs dos ingredientes e podem apresentar maior viscosidade no intestino delgado, menor fluxo no trato gastrintestinal, o que resulta maior fermentação bacteriana. Com relação ao milheto, não foram encontrados dados na literatura sobre $o$ percentual de PNAs.

Os dados de desempenho dos frangos alimentados com rações contendo sorgo ou milheto e suplementadas com complexo enzimático no período de um a sete dias de idade (Tab. 3) mostram que não houve diferença $(\mathrm{P}>0,05)$ entre os ingredientes energéticos utilizados na ração sobre o desempenho de pintos de corte. 
Tabela 3. Desempenho de frangos de corte alimentados com rações contendo milheto ou sorgo e suplementadas com complexo enzimático (CE), de 1 a 7 dias de idade

\begin{tabular}{lcccc} 
Tratamento & $\begin{array}{c}\text { Peso final } \\
(\mathrm{g})\end{array}$ & $\begin{array}{c}\text { Ganho de peso } \\
(\mathrm{g})\end{array}$ & $\begin{array}{c}\text { Conversão alimentar } \\
(\mathrm{g} / \mathrm{g})\end{array}$ & $\begin{array}{c}\text { Consumo de } \\
\text { ração }(\mathrm{g})\end{array}$ \\
\hline Sorgo & 184,2 & 140,4 & 0,928 & 170,9 \\
Sorgo $+\mathrm{CE}$ & 185,4 & 142,0 & 0,795 & 152,6 \\
Milheto & 189,3 & 145,8 & 0,888 & 160,8 \\
Milheto + CE & 187,5 & 144,0 & 0,897 & 10,6 \\
\hline $\mathrm{CV}(\%)$ & 3,52 & 4,51 & 10,03 & $\mathrm{~ns}$ \\
\hline Análise de contraste & & & & $\mathrm{ns}$ \\
\hline Sorgo $x$ milheto & $\mathrm{ns}$ & $\mathrm{ns}$ & $\mathrm{ns}$ & $\mathrm{ns}$ \\
Sorgo $x$ sorgo CE & $\mathrm{ns}$ & $\mathrm{ns}$ & 0,0311 & $\mathrm{~ns}$ \\
Milheto $x$ milheto CE & $\mathrm{ns}$ & $\mathrm{ns}$ & & \\
\hline
\end{tabular}

ns= não significativo, teste de contraste (5\%).

A suplementação do complexo enzimático nas rações formuladas com sorgo melhorou $(\mathrm{P}<0,05)$ a conversão alimentar dos frangos na fase préinicial. Resultado semelhante foi encontrado por Gracia et al. (2003), que observaram melhor conversão alimentar e ganho de peso na fase préinicial quando adicionaram amilase em dietas com milho e farelo de soja para frangos. Estes resultados assemelham-se aos relatos de Noy e Sklan (2002), que consideraram a primeira semana de vida de pintos de corte como período de baixa reserva de enzimas pancreáticas e os processos de digestão e absorção ainda pouco eficientes. Segundo Noy e Sklan (1995), apesar de a secreção da amilase ser relativamente baixa para frangos jovens no quarto dia de idade e aumentar com a idade, a digestão do amido sempre foi acima de $85 \%$ entre o quarto e o $21^{\circ}$ dias de idade. Sakomura et al. (2004) observaram aumento linear da amilase de acordo com a idade das aves, assim como o crescimento alométrico do pâncreas, e Sakamoto (2009) encontrou maior concentração da amilase e lipase aos 14 dias e da tripsina aos sete dias de idade de frangos de corte.

No período de um a 35 dias de idade (Tab. 4), houve diferença $(\mathrm{P}<0,05)$ do tipo de ingrediente energético sobre o peso final, ganho de peso e conversão alimentar. Pode-se observar que as rações formuladas com milheto proporcionaram $(\mathrm{P}<0,05)$ melhores resultados quando comparadas às rações elaboradas com sorgo.

Tabela 4. Desempenho de frangos de corte alimentados com rações contendo milheto ou sorgo e suplementadas com complexo enzimático, 1 a 35 dias

\begin{tabular}{|c|c|c|c|c|}
\hline Tratamento & Peso final $(\mathrm{kg})$ & $\begin{array}{l}\text { Ganho de } \\
\text { peso }(\mathrm{kg})\end{array}$ & $\begin{array}{c}\text { Conversão alimentar } \\
(\mathrm{kg} / \mathrm{kg})\end{array}$ & $\begin{array}{l}\text { Consumo de } \\
\text { ração (kg) }\end{array}$ \\
\hline Sorgo & 2,16 & 2,11 & 1,537 & 3,14 \\
\hline Sorgo + CE & 2,19 & 2,14 & 1,515 & 3,13 \\
\hline Milheto & 2,27 & 2,22 & 1,428 & 3,08 \\
\hline Milheto + CE & 2,31 & 2,27 & 1,428 & 3,12 \\
\hline $\mathrm{CV}(\%)$ & 1,57 & 1,61 & 2,73 & 2,9 \\
\hline \multicolumn{5}{|l|}{ Análise de contraste } \\
\hline Sorgo $\mathrm{x}$ milheto & $<0,001$ & $<0,001$ & $<0,001$ & ns \\
\hline Sorgo $\mathrm{x}$ sorgo $\mathrm{CE}$ & ns & ns & ns & ns \\
\hline Milheto $\mathrm{x}$ milheto $\mathrm{CE}$ & 0,046 & 0,0470 & ns & ns \\
\hline
\end{tabular}

ns - não significativo, teste de contraste (5\%).

Com relação à suplementação do complexo enzimático, não foi observado $(\mathrm{P}>0,05)$ efeito da adição de enzimas em rações com sorgo, enquanto nas rações com milheto, a suplementação de enzimas aumentou $(\mathrm{P}<0,05) \mathrm{o}$ peso vivo e o ganho de peso. Esses resultados concordam parcialmente com os estudados por Strada et al. (2005), que não verificaram efeito 
do complexo enzimático (protease, amilase e xilanase) em rações elaboradas com milheto e sorgo sobre o ganho de peso, o consumo de ração e a conversão alimentar até 21 dias de idade.

No período total de criação, de um a 42 dias de idade (Tab. 5), houve efeito do ingrediente energético utilizado sobre o desempenho de frangos, sendo que as rações com milheto proporcionaram melhor peso final e ganho de peso $(\mathrm{P}<0,05)$ em relação às raçoes elaboradas com sorgo.

A suplementação do complexo enzimático nas rações não melhorou o desempenho de frangos no período total de criação $(\mathrm{P}>0,05)$. Resultado semelhante foi verificado por Morais et al. (2002), que estudaram rações elaboradas com sorgo e não verificaram efeito do complexo enzimático composto por protease, amilase e betaglucanase sobre peso vivo no período total de criação (42 dias de idade). Do mesmo modo, Santos et al. (2006), em estudo com frangos alimentados com dietas elaboradas com sorgo e suplementadas com complexo enzimático (protease, amilase e xilanase), não observaram diferença no consumo de ração, ganho de peso e conversão alimentar aos 42 dias de idade.
Em outros estudos nos quais foi avaliado o efeito de complexos enzimáticos adicionados em rações elaboradas com milho e farelo de soja, houve efeito positivo das enzimas sobre a conversão alimentar de frangos de corte na fase de crescimento (Tahir et al., 2005; Cowieson e Adeola, 2005) e no período total de criação (Toledo et al., 2007). Estes resultados sugerem que a ação de enzimas exógenas em rações de frango pode modificar em razão do tipo de ingrediente utilizado na ração. De acordo com Tejedor et al. (2001), na suplementação com enzimas é importante o conhecimento da composição dos ingredientes utilizados na ração e da especificidade da enzima com relação ao substrato.

Neste experimento, o complexo enzimático utilizado melhorou a conversão alimentar na fase pré-inicial com sorgo bem como o ganho de peso na fase de crescimento em rações com sorgo ou milheto, no entanto, para o período total, não foi observado efeito positivo das enzimas, e os resultados observados podem estar relacionados ao fato de que o complexo enzimático comercial utilizado foi desenvolvido para rações elaboradas com milho.

Tabela 5. Desempenho de frangos de corte alimentados com rações contendo milheto ou sorgo e suplementadas com complexo enzimático (CE), 1 a 42 dias

\begin{tabular}{lcccc}
\hline Tratamento & $\begin{array}{c}\text { Peso final } \\
(\mathrm{kg})\end{array}$ & $\begin{array}{c}\text { Ganho de } \\
\text { peso }(\mathrm{kg})\end{array}$ & $\begin{array}{c}\text { Conversão alimentar } \\
(\mathrm{kg} / \mathrm{kg})\end{array}$ & $\begin{array}{c}\text { Consumo de } \\
\text { ração }(\mathrm{kg})\end{array}$ \\
\hline Sorgo & 2,66 & 2,61 & 1,649 & 4,06 \\
Sorgo + CE & 2,64 & 2,59 & 1,649 & 4,04 \\
Milheto & 2,79 & 2,75 & 1,621 & 4,12 \\
Milheto + CE & 2,77 & 2,73 & 1,585 & 3,93 \\
\hline CV $(\%)$ & 4,19 & 4,26 & 3,20 & 4,32 \\
\hline Análise de contraste & & & & $\mathrm{ns}$ \\
\hline Sorgo $x$ milheto & 0,0172 & 0,0172 & $\mathrm{~ns}$ & $\mathrm{~ns}$ \\
Sorgo $x$ sorgo CE & $\mathrm{ns}$ & $\mathrm{ns}$ & $\mathrm{ns}$ & $\mathrm{ns}$ \\
Milheto $x$ milheto CE & $\mathrm{ns}$ & $\mathrm{ns}$ & & \\
\hline
\end{tabular}

ns - não significativo, teste de contraste (5\%).

Este estudo mostra que a idade dos frangos, os ingredientes que compõem as rações e o tipo de enzimas utilizadas no complexo podem influenciar a eficácia do produto enzimático, assim como outros fatores: a forma e o momento de aplicação das enzimas, a exposição a altas temperaturas, a aplicação em quantidades precisas e a distribuição uniforme nas rações. As enzimas adicionadas nas rações podem também ser destruídas durante o processamento, antes mesmo do oferecimento da dieta ao animal, além disso, parte das enzimas exógenas pode ser inativada após a ingestão da ração, devido às condições ácidas do trato gastrintestinal, bem 
como à ação das enzimas proteolíticas endógenas (Sieo et al., 2005).

\section{CONCLUSÕES}

A adição de enzimas em rações com milheto ou sorgo não altera a população das bactérias aeróbias e coliformes totais no intestino delgado. A utilização do complexo enzimático comercial em rações com sorgo ou milheto melhora os resultados de desempenho, dependendo da idade dos frangos.

\section{REFERÊNCIAS}

APAJALAHTI, J.H.A.; KETTUNEN, A.; BEDFORD, M.R. et al. Percent G+ C profiling accurately reveals diet-related differences in the gastrointestinal microbial community of broiler chickens. Appl. Environ. Microbiol., v.67, p.5656-5667, 2001.

BEDFORD, M.R. Exogenous enzymes in monogastric nutrition-their current value and future benefits. Anim. Feed Sci. Technol., v.86, p.1-13, 2000.

BRASIL. Ministério da Agricultura, Pecuária e Abastecimento, Secretaria de Defesa Agropecuária. Métodos Analíticos Oficiais para Análises Microbiológicas para Controle de Produtos de Origem Animal e Água. Instrução Normativa $n^{\circ}$ 62, de 26/08/2003. Diário Oficial da União, Brasília, seção I, p.14-51, 18 set. 2003.

BRITO, C.O.; ALBINO, L.F.T.; ROSTAGNO, H.S. et al. Adição de complexo multienzimático em dietas à base de soja extrusada e desempenho de pintos de corte. Rev. Bras. Zootec., v.35, p.457-461, 2006.

COWIESON, A.J.; ADEOLA, O. Carbohydrases, protease, and phytase have an additive beneficial effect in nutritionally marginal diets for broiler chicks. Poult. Sci., v.84, p.1860-1867, 2005.

DANICKE, S.; VAHJEN, W.; SIMON, O. et al. Effects of dietary fat type and xylanase supplementation to rye-based broiler diets on selected bacterial groups adhering to the intestinal epithelium, on transit time of feed, and on nutrient digestibility. Poult. Sci., v.78, p.1292-1299, 1999.
GAO, F.; JIANG, Y.; ZHOU, G.H. et al. The effects of xylems supplementation on performance, characteristics of the gastrointestinal tract, blood parameters and gut microflora in broilers fed on wheat-based diets. Anim. Feed Sci. Technol., v.142, p.173-184, 2008.

GRACIA, M.I.; ARANÍBAR, M.J.; LÁZARO, R. et al. a Amylase supplementation of broiler diets based on corn. Poult. Sci., v.82, p.436-442, 2003.

MALATHI, V.; DEVEGOWDA, G. In vitro evaluation of nonstarch polysaccharide digestibility of feed ingredients by enzymes. Poult. Sci., v.80, p.302-305, 2001.

MATHLOUTHI, N.; MALLET, S.; SAULNIER, L. et al. Effects of xylanase and $\beta$ - glucanase addition on performance, nutrient digestibility, and physico-chemical conditions in the small intestine contents and caecal microflora of broiler chickens fed a wheat and barley-based diet. Anim. Res., v.51, p.395-406, 2002.

MORAIS, E.; FRANCO, S.G.; FEDALTO, L.M. Efeitos da substituição do milho pelo sorgo, com adição de enzimas digestivas, sobre o ganho médio de peso de frangos de corte. Arch. Vet. Sci, v.7, p.109-114, 2002.

NOY, Y.; SKLAN, D. Digestion and absorption in the young chick. Poult. Sci., v.74, p.366-373, 1995.

NOY, Y.; SKLAN, D. Nutrient use in chicks during the first week postahartch. Poult. Sci., v.81, p.391-399, 2002.

ODETALLAH, N.H.; WANG, J.J.; GARLICH, J.D. et al. Versazyme supplementation of broiler diets improves market growth performance. Poult. Sci., v.84, p.858-864, 2005.

OLIVEIRA, M.C.; CANCHERINI, L.C.; GRAVENA, R.A. et al. Utilização de nutrientes de dietas contendo mananoligossacarídeo e/ou complexo enzimático para frangos de corte. Rev. Bras. Zootec., v.36, p.825-831, 2007.

OLUKOSI, O.A.; COWIESON, A.J.; ADEOLA, O. et al. Age-related influence of a cocktail of xylanase, amylase and protease or phytase individually or in combination in broilers. Poult. Sci., v.86, p.77-86, 2007. 
OPALINSKI, M.; MAIORKA, A.; CUNHA, F. et al. Adição de níveis crescentes de complexo enzimático em rações com soja integral desativada para frangos de corte. Arch. Vet. Sci., v.11, p.31-35, 2006.

REDDY, K.V.; MALATHI, V.; VENKATARAMI REDDYS, B.S. Effect of finger millet and sorghum replacing corn in presence of soy oil/fish oil and enzymes on performance of broilers. Int. J. Poult. Sci., v.6, p.560-564, 2008.

ROSTAGNO, H.S.; ALBINO, L.F.T.; DONZELE, J.L. et al. Tabelas brasileiras para aves e suínos: composição de alimentos $e$ exigências nutricionais. Viçosa: UFV-Imprensa Universitária, 2005.187p.

SAKAMOTO, M.I. Desempenho, desenvolvimento e atividade enzimática da mucosa intestinal de frangos de corte alimentados com dietas suplementadas com glutamina e nucleotídeos. 2009. 95f. Tese (Doutorado em Zootecnia) - Universidade de São Paulo, São Paulo, SP.

SAKOMURA, N.K.; BIANCHI, M.; PIZAURO JUNIOR, J.M. et al. Efeito da idade dos frangos de corte na atividade enzimática e digestibilidade dos nutrientes do farelo de soja e da soja integral. Rev. Bras. Zootec., v.33, p.924-935, 2004.

SANTOS, M.S.V.; ESPÍNDOLA, G.B.; FUENTES, M.F.F. et al. Utilização de complexo enzimático em dietas à base de sorgo-soja para frangos de corte. Rev. Bras. Zootec., v.35, p.811$817,2006$.

SANTOS JR, A.A.; FERKET, P.R. Fatores dietéticos que afetam a saúde intestinal e a colonização por patógenos. In: CONFERÊNCIA APINCO DE CIÊNCIA E TECNOLOGIA AVÍCOLA, 2007, Santos. Anais... Santos: FACTA, 2007. p.143-159.

SARICA, S.; CIFTCI, A.; DEMIR, E. et al. Use of an antibiotic growth promoter and two herbal natural feed additives with and without exogenous enzymes in wheat based broiler diets. S. Afr. J. Anim. Sci., v.35, p.61-72, 2005.
SIEO, C.C.; ABDULLAH, N.; TAN, W.S. et al. Influence of $\beta$-glucanase-producing lactobacillus strains on intestinal characteristics and feed passage rate of broiler chickens. Poult. Sci., v.84, p.734-741, 2005.

STATISTICAL Analisys System-SAS Institute Inc., SAS/STAT. User's guide. Versão 6.11. 4.ed., v.2. Cary: SAS Institute Inc., 2000. 842 p.

STRADA, E.S.O.; ABREU, R.D.; OLIVEIRA, G.J.C.O. et al. Uso de enzimas na alimentação de frangos de corte. Rev. Bras. Zootec., v.34, p.2369-2375, 2005 .

TAHIR, M.; SALEH, F.; OHTSUKA, A. et al. Synergistic effect of cellulase and hemicellulase on nutrient utilization and performance in broilers fed a corn-soybean meal diet. Anim. Sci. J., v.76, p.559-565, 2005.

TEJEDOR, A.A.; ALBINO, L.F.T.; ROSTAGNO, H.S. et al. Efeito da adição de enzimas em dietas de frangos de corte à base de milho e farelo de soja sobre a digestibilidade ideal de nutrientes. Rev. Bras. Zootec., v.30, p.809-816, 2001.

TOLEDO, G.S.P.; COSTA, P.T.C.; SILVA, J.H. et al. Frangos de corte alimentados com dietas de diferentes densidades nutricionais suplementadas ou não com enzimas. Cienc. Rural, v.37, p.518523, 2007.

WANG, Z.R.; QIAO, S.Y.; LU, W.Q. et al. Effects of enzyme supplementation on performance, nutrient digestibility, gastrointestinal morphology, and volatile fatty acid profiles in the hindgut of broilers fed wheatbased diets. Poult. Sci., v.84, p.875-881, 2005. 